\begin{tabular}{|c|c|}
\hline 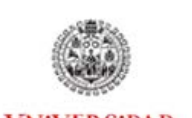 & $\begin{array}{c}\text { Teoría de la Educación } \\
\text { Educación y Cultura en la }\end{array}$ \\
\hline $\begin{array}{l}\text { VNIVERSIDAD } \\
\text { DSALAMANCA }\end{array}$ & Sociedad de la Información \\
\hline
\end{tabular}

\title{
EL USO DE MINIJUEGOS EN LA ENSEÑANZA-APRENDIZAJE DE FÍSICA Y QUÍMICA DE BACHILLERATO
}

\author{
Felipe QUINTANAL PÉREZ
}

Colegio Marista "La Inmaculada" (Granada)

Departamento de Ciencias y Tecnología

felipeqp@ maristasmediterrranea.com

\section{Resumen:}

El proyecto realizado se ha cimentado en el empleo de minijuegos educativos gratuitos que guarden alguna relación con la materia de Física y Química. Esta temática ha sido seleccionada por consenso con los alumnos en base a las utilidades didácticas de los videojuegos, a la seducción que ejercen sobre los estudiantes y a la mejora en el desarrollo de sus habilidades TIC. Esta acción se realizó durante el curso 2012-2013 con alumnos de $1^{\circ}$ de Bachillerato de las modalidades de salud y científico-tecnológica. Los estudiantes se organizaron por equipos de trabajo heterogéneos e inicialmente seleccionaron y analizaron minijuegos. Una vez escogidos, realizaron las siguientes tareas: una revista digital, una fotografía interactiva, un test multimedia y un cartel de presentación. Estas actividades fueron compartidas en la red social Edmodo. A tenor de los resultados obtenidos en la autoevaluación efectuada por los alumnos, se puede consideran la ejecución de este proyecto como un éxito.

Palabras clave: Minijuegos, Bachillerato, Física y Química, Edmodo, Herramientas Web 2.0.

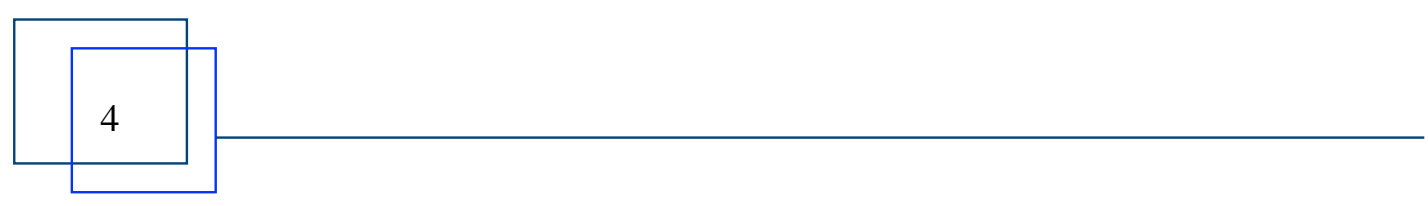




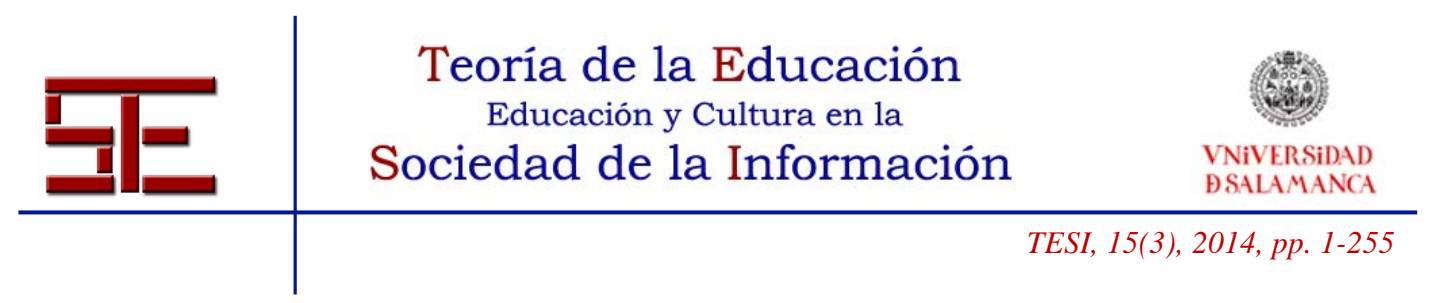

\title{
USE OF MINI-GAMES IN TEACHING-LEARNING OF PHYSICS AND CHEMISTRY OF HIGH SCHOOL
}

\begin{abstract}
:
The project has built on the use of free educational minigames that are unrelated to the subject matter of physics and chemistry. This theme has been selected by consensus with the students based on the educational profits from video games, seduction of students and improve their ICT skills. This action was developed during the academic year 2012-2013 with students of 1st Bachelor for modalities of health and science and technology. Students organized by heterogeneous teams initially selected and analyzed minigames. Once chosen, they carried out the following tasks: a digital magazine, an interactive picture, a multimedia test and a poster. These activities were shared on the social network Edmodo. According to the results of the self-evaluation carried out by the students, it can be concluded that the project has been a success.
\end{abstract}

Key words: Mini-games, High School, Physics and Chemistry, Edmodo, Web 2.0 Tools. 


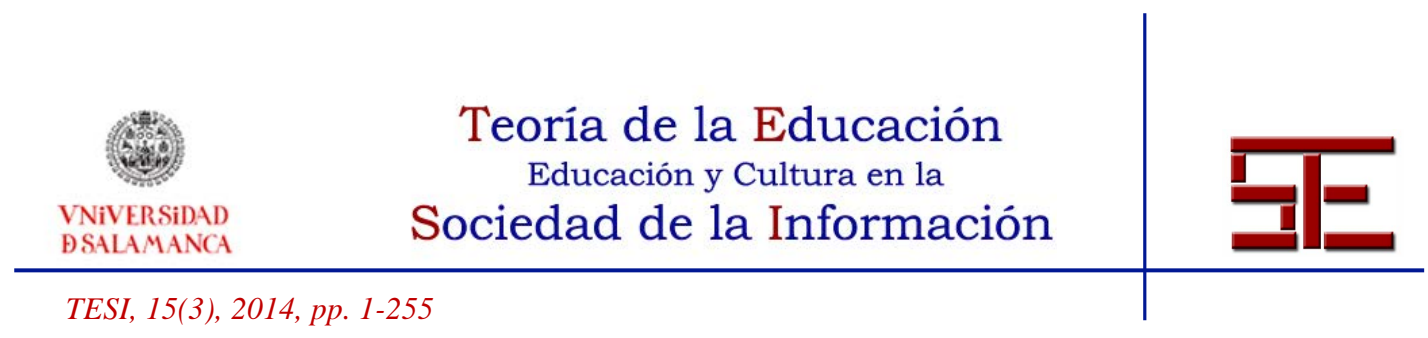

\section{INTRODUCCIÓN}

Los nuevos medios de comunicación influyen en la sociedad actual, encontrándose presentes en nuestra vida cotidiana, en el trabajo y durante los momentos de ocio. Las generaciones nuevas crecen acompañadas de las nuevas tecnologías, las conocen y se conectan a través de ellas. Dentro de este mundo tecnológico, los videojuegos son uno de los medios que más éxito tienen entre los más jóvenes y por tanto consideramos que la educación no debe permanecer ausente ante este hecho. Esta es la razón por la que los videojuegos se han elegido como núcleo de esta investigación. Creemos en su potencial a la hora de introducirlos en los procesos de aprendizaje para adquirir competencias y habilidades que favorezcan la alfabetización digital (Jenkins, 2006a).

Actualmente hay docentes que se interesan por introducir estos medios en sus aulas para aprender con ellos. Eso hace necesario realizar un análisis del medio y la búsqueda de estrategias que nos conduzcan a desarrollar nuevos estilos de enseñanza, nuevas concepciones del aprendizaje y nuevas formas de gestión escolar; es decir, si se contemplan los videojuegos como herramientas educativas, ello comporta una consideración de la educación diferente. Esta concepción del aprendizaje y el reconocimiento del valor educativo de estos medios hacen necesaria la creación de escenarios educativos innovadores.

En este contexto se propone un proyecto en el que se introducen los videojuegos junto a otros medios tecnológicos. Nuestra finalidad fue explorar el poder educativo de estos nuevos recursos educativos.

¿Por qué introducir los videojuegos en la enseñanza? Los videojuegos constituyen una de las "formas culturales emergentes" más importantes del momento, ocupando mucho tiempo de ocio de niños y adolescentes (Livingstone, 2002). En ese sentido estos entornos están generando un nuevo escenario para la comunicación en el que los elementos clásicos de esta evolucionan. Los jugadores comparten una forma de ocio, habilidades tecnológicas, la inmersión en un mundo virtual y multimedia y la experiencia concreta de rastrear un universo simbólico diferente. De esta manera, interaccionando con ellos se descubren razones nuevas para aproximarse a las situaciones presentes en la vida cotidiana de los adolescentes.

Algunos autores como Gee (2003) y Jenkins (2006a) se refieren a este proceso de transformación de los medios audiovisuales. Sus trabajos buscan el estilo de educar a los jóvenes para vivir en un universo versátil creado por las tecnologías de la información y la comunicación. Tomando este pensamiento como punto de partida de la investigación, se destacan tres ideas que nos parecen clave en relación al uso concreto de los videojuegos:

- Aprender y/o afianzar contenido curricular con los videojuegos. Alcanzar los

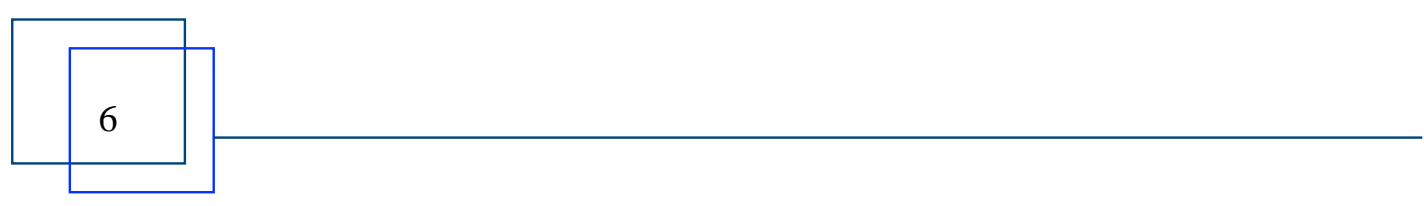




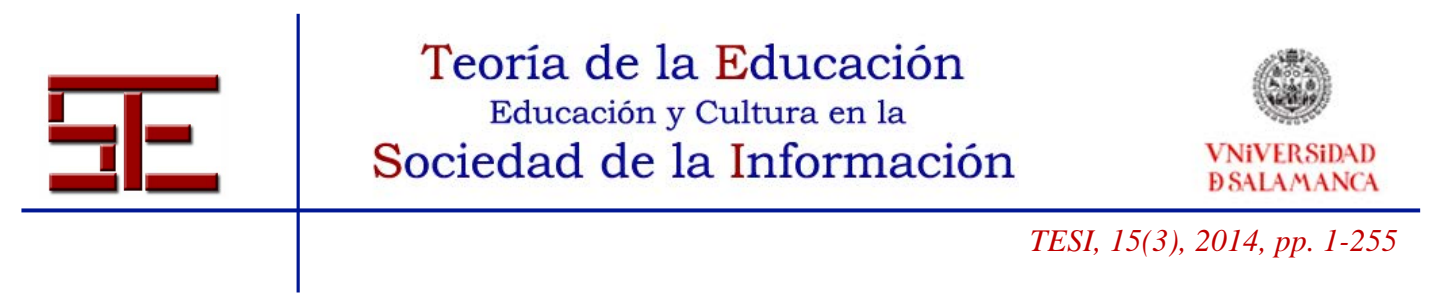

contenidos curriculares es una preocupación permanente entre los docentes, pero las metodologías y el conocimiento que se debe adquirir en las aulas no siempre motivan a los estudiantes. Habitualmente el cine, la televisión o los periódicos han sido buenos aliados para motivarlos, así que actualmente los videojuegos puede jugar también ese papel.

- Adquirir nuevos lenguajes y modelos de pensamiento. Pensar en la capacidad para representar una realidad es el primer paso hacia el conocimiento de lo que se puede aprender de ellos. Los videojuegos guardan un currículum oculto tras sus pantallas, del cual se puede aprender mientras se resuelve la trama del juego (Gee, 2010).

- Integrar con otras tecnologías. Nos referimos a las tecnologías de la información y la comunicación. No suelen ser excluyentes sino, más bien, tienden a complementarse entre sí. La presencia combinada de otras herramientas permite la comunicación y la expresión de uno mismo mediante diferentes lenguajes, es decir, no solo a través del texto escrito sino también a través del discurso audiovisual (Jenkins, 2006a).

Corresponde, por tanto, reseñar qué se entiende por videojuego en esta investigación. Así, "se podría definir como un hiperlenguaje dinámico-proyectivo, es decir, un instrumento que incluye diversos tipos de lenguaje distintos, como son el visual, el sonoro, el literario, gestual... todos ellos encuadrados en un mundo cambiante y dúctil a elección del creador del mismo y de los usuarios" (Revuelta y Guerra, 2012, 2).

Dada la imposibilidad de emplear videojuegos comerciales, se optó por emplear minijuegos en formato Flash. Estos constituyen un tipo de videojuego, pertenecientes al género de juegos rápidos, con las características principales de los videojuegos, pero con grados limitados de complejidad y sofisticación. En todo el desarrollo teórico que se presentará, se empleará la expresión de videojuego en vez de minijuego, por ser más genérica y por haber sido estudiada más ampliamente.

De ahí que el presente artículo se estructure en base a un marco referencial, objetivos buscados, contexto implicado, metodología utilizada, desarrollo del proyecto, logros conseguidos y conclusiones de la experiencia. El marco teórico se basa en indicar cuáles son los beneficios aportados por el uso de minijuegos, en la clasificación utilizada en esta experiencia educativa y en expresar cómo se pueden trabajar las competencias en estos escenarios nuevos.

\section{BENEFICIOS APORTADOS POR LOS VIDEOJUEGOS}

La literatura científica se muestra clara en cuanto a la siguiente premisa. Se puede aprender jugando con videojuegos, siempre y cuando haya supervisión; por tanto, deberían ser tratados en la escuela por aunar aspectos controvertidos y elementos interesantes. Los videojuegos pueden tener efectos positivos en el desarrollo de ciertas

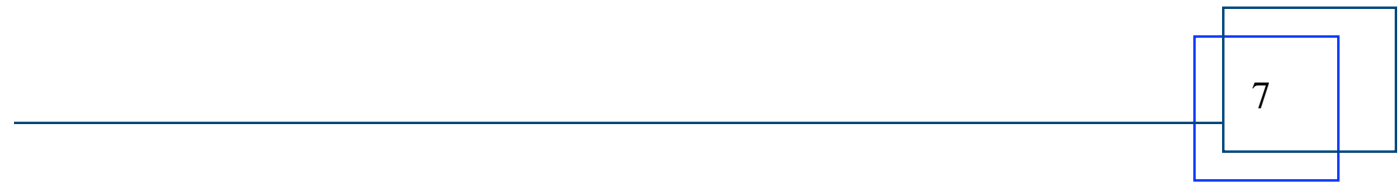




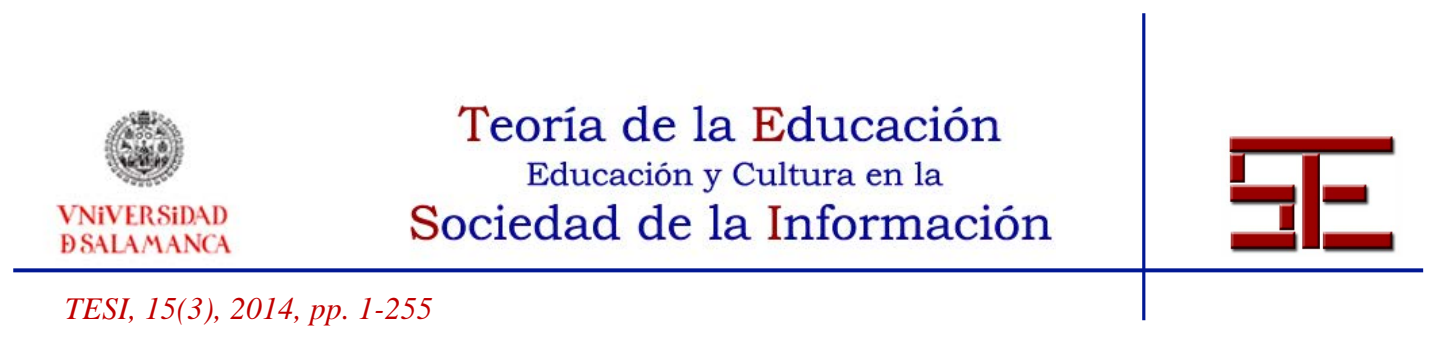

habilidades y destrezas en niños y en jóvenes. Un uso metodológico adecuado de los videojuegos en el aula puede incluso fomentar el trabajo cooperativo entre alumnos y docentes.

Así las diversas funciones de los videojuegos que pueden ayudar al aprendizaje se presentan en la Figura 1 (Vida y Hernández, 2005).

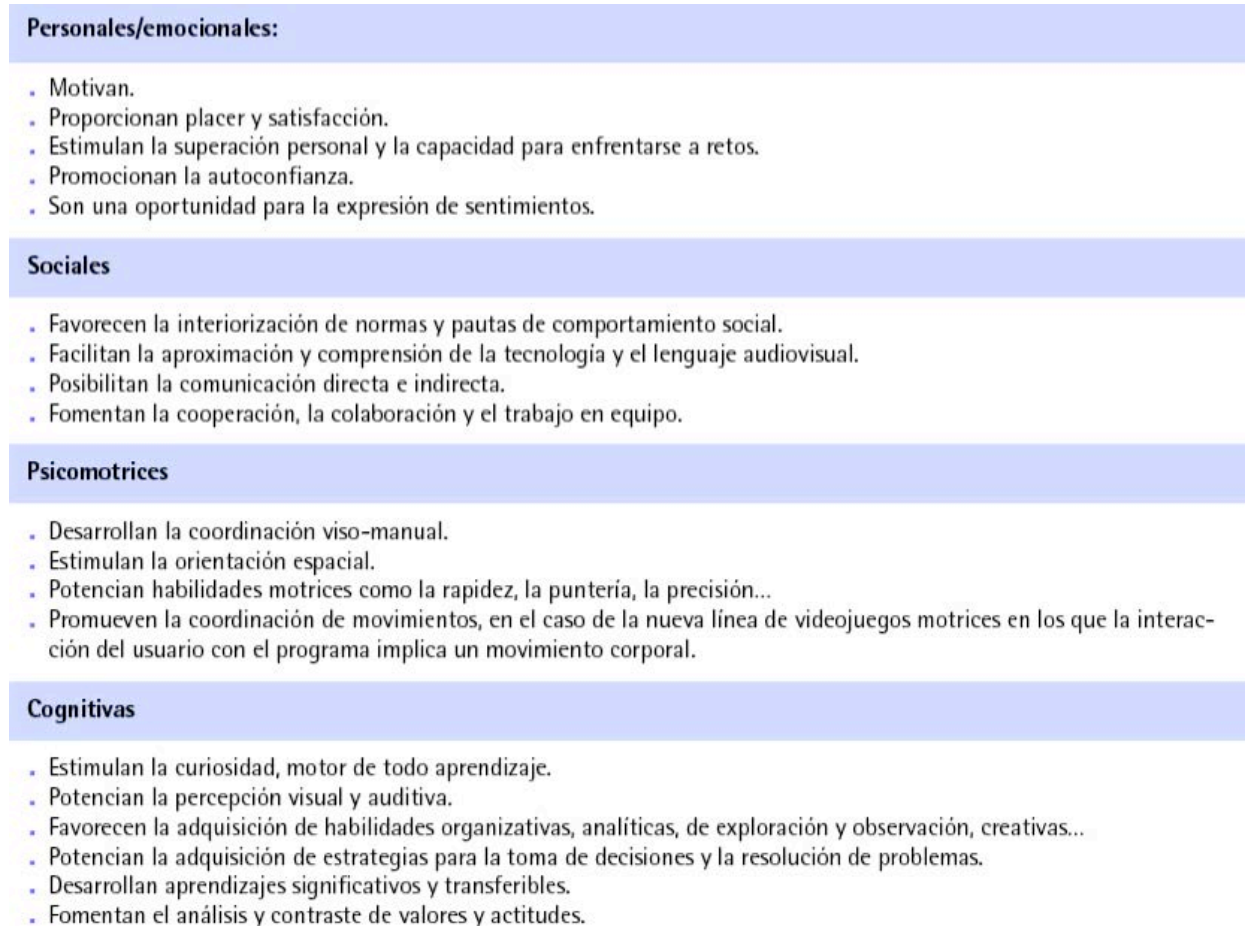

Figura 1. Potencial educativo de los videojuegos (Fuente: Vida y Hernández, 2005).

Por otro lado, la secuencia de aspectos reforzados por el uso de videojuegos es coincidente con la expuesta por Gómez del Castillo (2007, 4), destacando:

a. Aspectos cognitivos:

- Memorización de hechos.

- Observación hacia los detalles.

- Percepción y reconocimiento espacial.

- Descubrimiento inductivo.

- Capacidades lógicas y de razonamiento.

- Comprensión lectora y vocabulario.

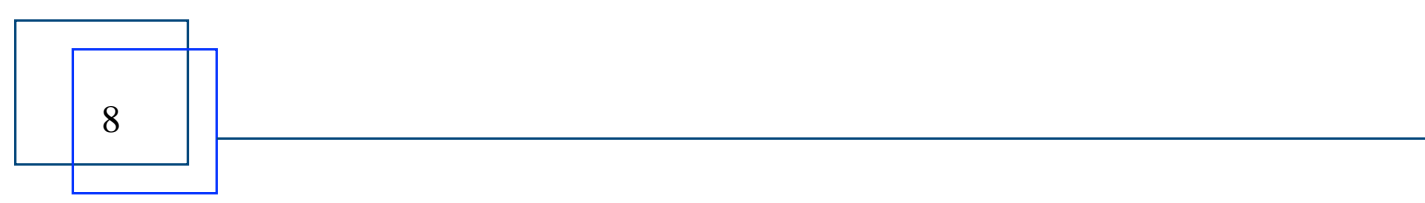




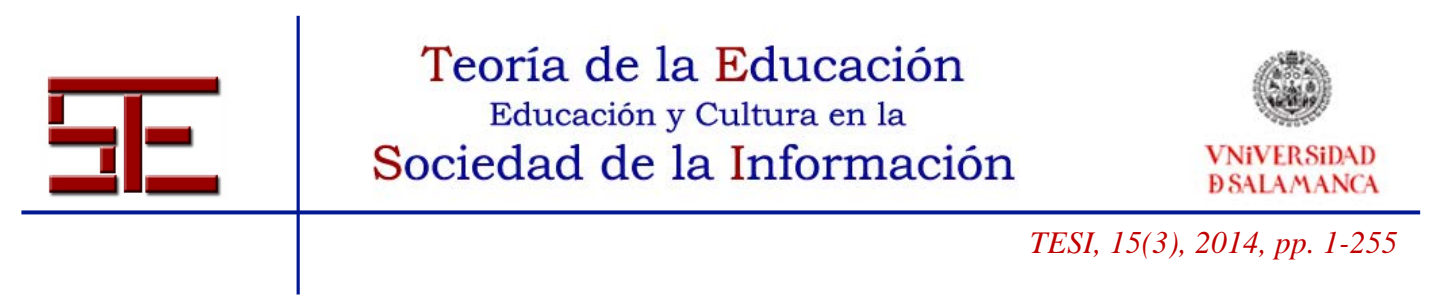

- Conocimientos geográficos, históricos, matemáticos...

- Resolución de problemas y planificación de estrategias.

b. Destrezas y habilidades:

- Autocontrol y autoevaluación.

- Implicación y motivación. Instinto de superación.

- Inversión de esfuerzo, reconocido de forma inmediata.

- Habilidades motrices, de reflejos y respuestas rápidas.

- Percepción visual, coordinación óculo-manual y percepción espacial.

- Curiosidad e inquietud por probar y por investigar.

c. Aspectos socializadores:

- Aumenta la autoestima: los videojuegos proporcionan un sentido de dominio, control y cumplimiento. Esto es debido, en gran parte, a que existen recompensas personalizadas.

- Interacción con amigos de manera no jerárquica (presencial o a distancia).

d. Alfabetización digital:

- Suele ser la herramienta para introducir al niño en el mundo de la informática: manejo de ventanas, comprensión de iconos, velocidad en el manejo del ratón... A veces, esto lleva a que el adulto piense que el niño sabe más de las TIC que él y se inhiba de su supervisión.

\section{TAXONOMÍA DE LOS VIDEOJUEGOS}

Existen diversos tipos de taxonomías de videojuegos. En esta investigación-acción se han seguido dos clasificaciones que han ayudado a seleccionar los minijuegos empleados y a su forma de uso.

Por un lado, se ha empleado la categorización de Squire que intenta resumir los diferentes géneros del juego a partir del tipo de narrativa del juego, del tiempo que hay que dedicar al juego, así como de los modos de expresión creativa que maneja, como se aprecia en la Figura 2.

Por otra parte, se ha seguido la propuesta de la European Schoolnet (Felicia, 2009) y que comprende los siguientes tipos de videojuegos:

- Juegos de disparos (o "shooter"): el jugador resuelve el conflicto disparando a sus oponentes. Pueden ser estáticos o dinámicos. En los estáticos, la pantalla limita el campo de batalla, mientras que en los dinámicos solo se ve una parte de este. Se

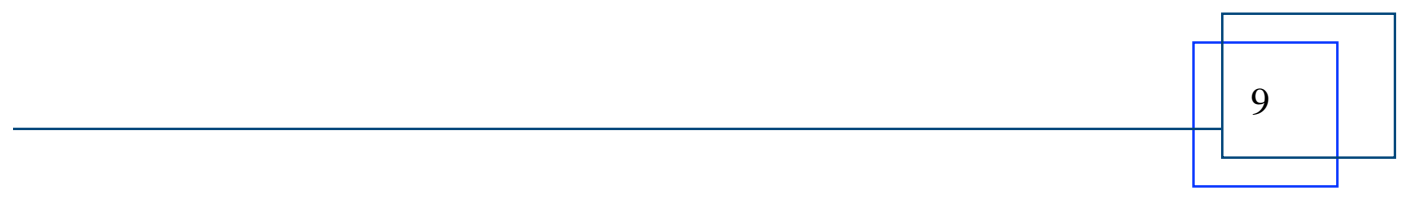




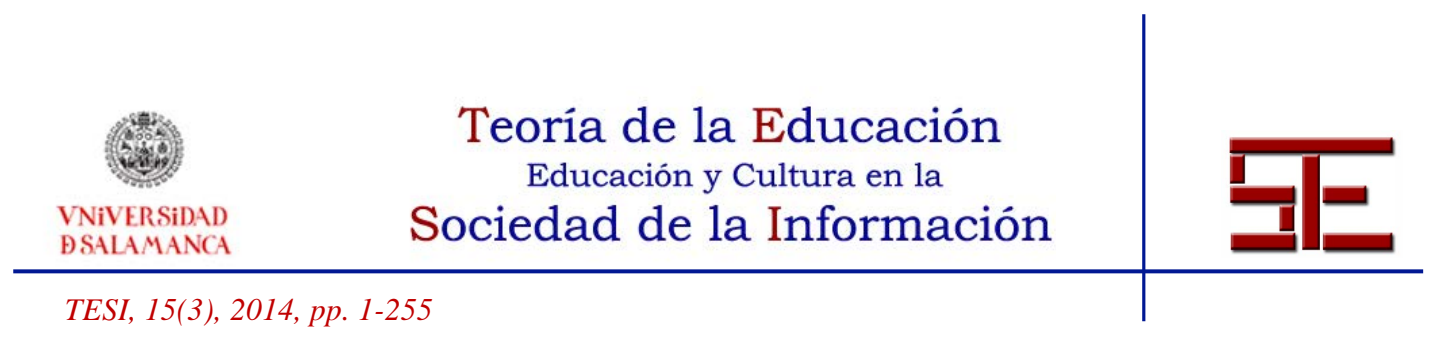

incluyen en este bloque los juegos de combate cuerpo a cuerpo. Los juegos de disparos inciden principalmente en los reflejos y en la coordinación. Como ejemplos se destacan Re-Misión, lucha contra el cáncer e Immune Attack, sobre Inmunología.

- Juegos de bate y pelota: los jugadores utilizan un bate para golpear una pelota. El juego más clásico conocido es Pong. Pertenece a este género 10 Finger BreakOut, un juego para aprender mecanografía.

- Juegos por plataformas: el jugador se desplaza en un espacio en el que tiene que avanzar por plataformas, de ahí su nombre. El ejemplo clásico es Mario. Se han desarrollado aplicaciones didácticas de este, como por ejemplo, para lectura, Mario's early years: fun with letters; para mecanografía, Mario teaches typing y para geografía, Mario is missing.

- Rompecabezas: los jugadores tienen que resolver un rompecabezas para avanzar en el juego. Suelen ser juegos de pantalla estática y el más conocido de este género es el Tetris. Se han desarrollado versiones pedagógicas para enseñar matemáticas como Prime Time: Math Adventure o Rocky's Boots.

- Laberintos: los jugadores se desplazan en un laberinto siendo perseguidos por enemigos que deben evitar. El paradigma es Pacman ("comecocos"). Suelen tener una vista cenital. Se requieren habilidades de planificación, estrategia y reflejos. Para mejorar en mecanografía se realizó una versión didáctica basada en Pacman, PacWriter.

- Juegos de rol: los jugadores encarnan un personaje de ficción. El personaje presenta varias características que pueden evolucionar a lo largo del juego. Como ejemplo se señala SimCity para destacar la gestión urbana y la construcción de ciudades.

- Juegos de rol multijugador masivos en línea: es una variante de los juegos de rol, con un gran número de participantes en línea e interactuando en escenarios virtuales simultáneamente. Este género de juego contribuye a las actividades exploratorias y de colaboración.

- Juegos de estrategia en tiempo real: los jugadores controlan los aspectos económicos y militares de un ejército o de una población. Por ejemplo, se destaca Civilization III que puede ayudar a los estudiantes a mejorar su comprensión de geografía e historia.

- Juegos de carreras: los jugadores participan en carreras de coches, motos o naves espaciales. Por ejemplo, Racing academy se ha usado para iniciar a los alumnos en conceptos de ingeniería.

- Juegos de deportes: reproducen deportes como fútbol, golf, baloncesto, rugby, etc. Están disponibles en 2D o en 3D y requieren de estrategia y coordinación, sobre todo si hay que administrar un equipo entero.

- Juegos de acción en primera persona: los jugadores ven el mundo desde los ojos del 


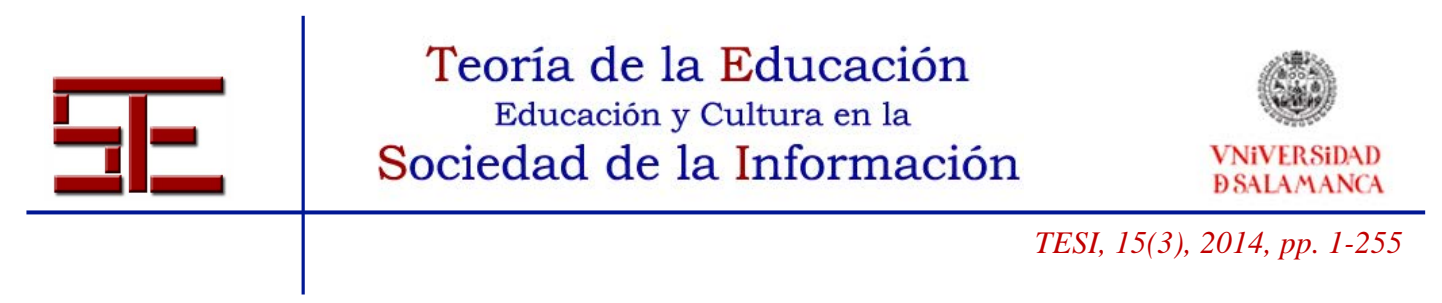

personaje que encarnan y han de deshacerse de los enemigos que se encuentran. Se puede jugar individual o colectivamente, fomentando, en este último caso, la colaboración. Son juegos que incluyen contenido violento, pero se han creado versiones pedagógicas que lo eliminan. Se destaca como ejemplo DimensionU para el aprendizaje de matemáticas.

- Juegos de mesa o de concursos televisivos: son las versiones educativas de algunos de estos juegos o concursos. Stu's Quiz Boxes representa un buen ejemplo de este género para enseñar cualquier materia y basado en el concurso Jeopardy.

- Juegos de aventuras gráficas: los jugadores recorren mundos complejos, recogen objetos y afrontan desafíos hasta cumplir con el objetivo final. Se basan en la narración de una historia. Se destacan King's Quest, en 2D y en 3D, EverQuest.

- Juegos serios: son juegos cuyo diseño original responde a los objetivos de enseñar, formar o concienciar. Pueden tratarse de juegos de noticias, de simulación o de dinámicas de organización. Como ejemplos se pueden citar Darfur está muriendo, desarrollada por mtvU, que permite conocer las condiciones de vida en los campos de refugiados de Darfur y Food force, supervisado por el Programa de Alimentación Mundial de Naciones Unidas, cuyos beneficios formativos son la ayuda humanitaria, la gestión y distribución de alimentos.

\begin{tabular}{|c|c|c|c|c|c|}
\hline Género & Tiempo & Frecuencia & $\begin{array}{l}\text { Final } \\
\text { abierto }\end{array}$ & $\begin{array}{l}\text { Modos } \\
\text { creativos }\end{array}$ & $\begin{array}{l}\text { Ejemplos } \\
\text { educativos }\end{array}$ \\
\hline $\begin{array}{l}\text { Juegos } \\
\text { rápidos } \\
\text { (puzzle, } \\
\text { minigames) }\end{array}$ & 1-4 horas & Semanal & Bajo & Bajo & Supercharged \\
\hline $\begin{array}{l}\text { Juegos } \\
\text { lineales }\end{array}$ & $\begin{array}{l}20-40 \\
\text { horas }\end{array}$ & Mensual & Bajo & Bajo & $\begin{array}{l}\text { Full } \\
\text { Spectrum, } \\
\text { Warrior, } \\
\text { epistemic } \\
\text { games }\end{array}$ \\
\hline $\begin{array}{l}\text { Juegos } \\
\text { abiertos }\end{array}$ & 100 horas & 2-24 meses & Alto & $\begin{array}{l}\text { Múltiples } \\
\text { soluciones y } \\
\text { alternativas }\end{array}$ & $\begin{array}{l}\text { Civilization, } \\
\text { Sim City, The } \\
\text { Sims }\end{array}$ \\
\hline $\begin{array}{l}\text { Mundos } \\
\text { persistentes }\end{array}$ & 500 horas & $6-48$ meses & Alto & $\begin{array}{l}\text { Juegos } \\
\text { sociales, } \\
\text { simulaciones }\end{array}$ & $\begin{array}{l}\text { Quest } \\
\text { Atlantis }\end{array}$ \\
\hline
\end{tabular}

Figura 2. Marco de referencia para la clasificación de juegos digitales (Fuente: Squire, 2008, 172 en Gros, 2012, 9). 


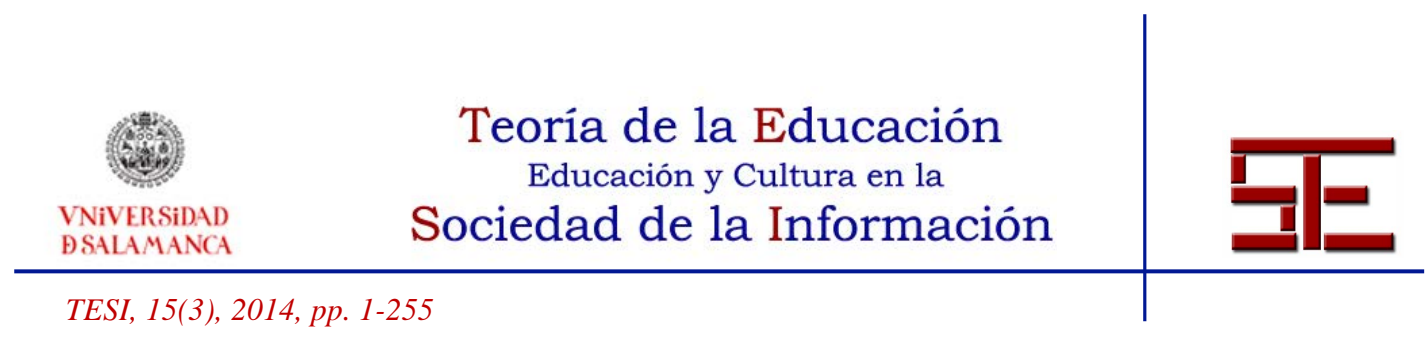

\section{NUEVAS COMPETENCIAS Y NUEVOS ESCENARIOS}

Los tiempos actuales requieren de una alfabetización multimodal según expresión de Gee (2003) para ser competente en la elaboración de textos multimodales, que pueden incluir lenguaje escrito, imágenes estáticas o dinámicas, símbolos, gráficos, diagramas, sonidos, sensaciones y otras maneras de expresión. Las nuevas tecnologías digitales son herramientas que requieren un cierto conocimiento de estos códigos por parte del usuario para comprender los mensajes que se transmiten en toda su complejidad. En este contexto, los videojuegos pueden introducir a los estudiantes en este mundo multimodal, ya que combinan diferentes lenguajes.

De este modo, tanto en contextos reales como en virtuales, los niños y adolescentes deben desarrollar destrezas que les ayuden a participar activamente en lo que Jenkins (2006a) ha denominado "cultura participativa". Como él mismo (Jenkins, 2006b) ha señalado, las escuelas como instituciones deben involucrarse de manera más consciente en esta nueva cultura participativa, promoviendo el desarrollo de un conjunto de competencias culturales y habilidades sociales que los jóvenes necesitan ante el nuevo paisaje mediático:

"Fomentar estas habilidades sociales y competencias culturales requiere un enfoque más sistemático de la educación en los medios. Todos los agentes involucrados en la formación de los jóvenes tienen que aportar para ayudar a los estudiantes a adquirir las habilidades que necesitan para convertirse en participantes plenos en nuestra sociedad. Las escuelas, los programas de actividades extraescolares y los padres, tienen diferentes roles que desempeñar y hacen lo que pueden en sus propios espacios para estimular y fomentar estas habilidades". (Jenkins et al, 2006b, 4).

De ahí se infiere que es especialmente relevante resaltar el conjunto de habilidades necesarias que implican saber leer y escribir en la sociedad digital (Jenkins, 2006b, en Del Castillo et al, 2012, 6-7):

1. Jugar: Capacidad para experimentar con el entorno como un espacio de resolución de problemas.

2. Representación: Capacidad de adoptar identidades alternativas con el objetivo de improvisar y descubrir.

3. Simulación: Capacidad de interpretar y construir modelos dinámicos de procesos del mundo real.

4. Apropiación: Posibilidad de probar de manera significativa y remezclar el contenido de los medios.

5. Multitarea: Capacidad de explorar el entorno y de centrarse, según sea necesario, en los detalles más destacados.

6. Cognición distribuida: Capacidad de interactuar de manera significativa con herramientas que amplían las capacidades cognitivas.

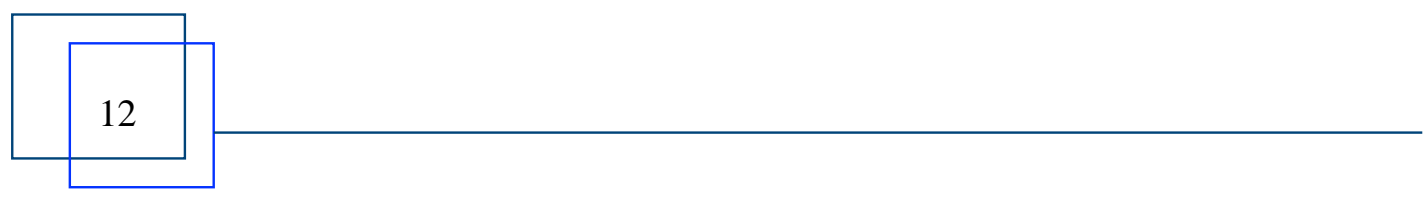




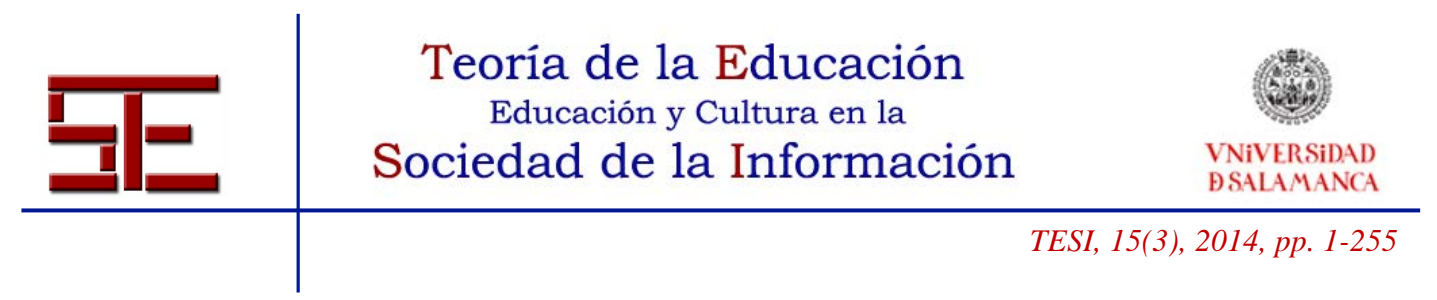

7. Inteligencia colectiva: Capacidad de compartir conocimientos con otros para lograr un objetivo común.

8. Juicio: Capacidad de evaluar la fiabilidad y la credibilidad de las diferentes fuentes de información.

9. Navegación transmedia: Capacidad para seguir el flujo de las historias y de la información a través de múltiples modalidades o medios.

10. Trabajo en red: Habilidad para buscar, sintetizar y difundir información.

11. Negociación: Posibilidad de moverse a través de las diversas comunidades, respetar, discernir múltiples perspectivas y adaptación a normas alternativas.

El proyecto de investigación-acción desarrollado con los estudiantes ha intentado potenciar las habilidades de jugar (1), multitarea (5), de cognición distribuida (6), juicio (8) y de trabajo en red (10), como se puede comprobar en las siguientes páginas.

\section{OBJETIVOS}

Los principales objetivos planteados en esta experiencia han sido:

- Incremento de los niveles de motivación del alumnado.

- Aumento del nivel de autoestima y autoconfianza de este.

- Mejora en la concentración y de distintos tipos de competencias, como las sociales, intelectuales (habilidad para cooperar y explorar, la independencia, la responsabilidad, la iniciativa y el dinamismo) y espacio-temporales (reflejos).

- Fomento de las producciones de los alumnos y compartición del conocimiento generado por estos.

- Desarrollo de las habilidades TIC de los estudiantes.

- Mejora en la preparación de futuros ciudadanos para los mundos virtuales presentes en la sociedad.

\section{CONTEXTO, METODOLOGÍA Y DESCRIPCIÓN DEL PROYECTO}

\subsection{Contexto y público objetivo}

La investigación educativa se ha realizado durante el curso 2012-2013 y se ha dirigido a 43 alumnos de $1^{\circ}$ de Bachillerato de las modalidades sanitaria (24 alumnos) y tecnológica (19 alumnos) que cursaban la asignatura de Física y Química. Por sexo, la distribución en la modalidad sanitaria fue de 9 alumnas y de 15 alumnos, mientras que en la modalidad tecnológica fue de 2 alumnas y 17 alumnos. En total, 11 alumnas y 32

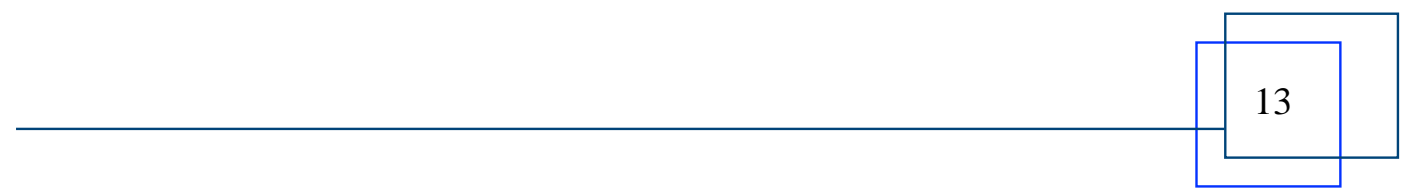




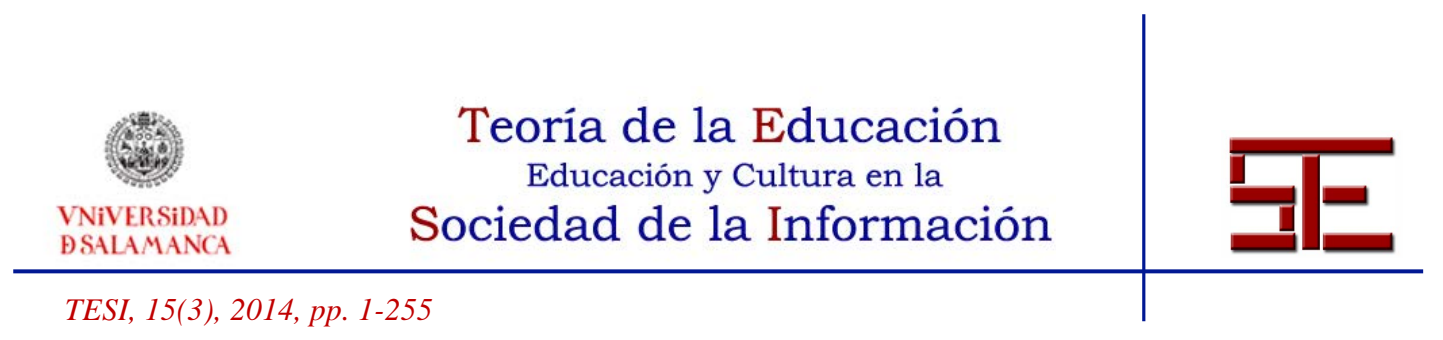

alumnos. De los 43 estudiantes, 42 provenían de cuarto de ESO y uno repetía primero de bachillerato. De los 42 discentes, 40 provenían del mismo centro y 2 llegaban de centros diferentes.

Los estudiantes han realizado su labor en un centro privado-concertado, en concreto, en la parte privada. Provienen de familias de clase acomodada y de nivel económico medio-alto. El nivel cultural de las familias es alto, pues en el $82 \%$ de ellas, alguno de los progenitores o los dos presentan nivel académico superior.

Los alumnos se encontraron inicialmente desorientados y estresados con la asignatura y la metodología que se seguía, notando de manera excesiva la diferencia entre ESO y Bachillerato. Con objeto de demostrar y ayudar a los estudiantes en su tarea concreta en Física y Química se planteó la realización de tareas relacionadas con videojuegos.

Los estudiantes, objeto de la investigación práctica realizada, mostraban interés por la ciencia y tecnología, estaban contentos con el nivel de la educación científica recibida hasta el momento y la información científica principalmente la obtenían de Internet. Además, usaban mayoritariamente Wikipedia como canal informativo y utilizaban al $100 \%$ las redes sociales, fundamentalmente Tuenti y Twitter, con fines encaminados al ocio y a la comunicación entre iguales.

\subsection{Metodología utilizada}

El diálogo con los estudiantes dirigió el proyecto hacia el trabajo con los videojuegos y, posteriormente, se concretó con los minijuegos. Rápidamente se pusieron de acuerdo con la idea de utilizar herramientas Web 2.0 gratuitas, desconocidas, para la ejecución de las diversas actividades.

Las principales desventajas que nos encontramos con el uso de los videojuegos en clase y que nos motivaron para utilizar minijuegos hacen referencia a dos ámbitos:

a. Los videojuegos

- Son recursos caros para la escuela y, en general, cada ordenador requiere un título con su propio número de registro.

- Muchos juegos no se pueden ejecutar en los equipos del centro al no estar estos actualizados tecnológicamente hablando.

- El diseño y los elementos utilizados en los videojuegos son factores que chocan con el horario escolar y que pueden molestar a las aulas vecinas.

- Hay pocos títulos desarrollados para uso escolar y los existentes, en general, son de inferior calidad que los comerciales.

b. La escuela

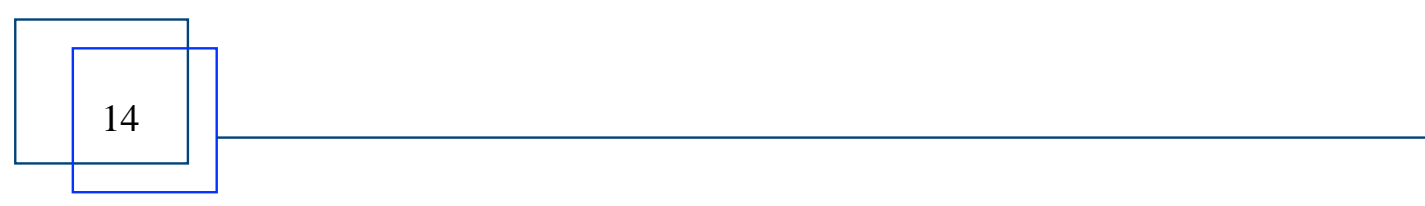




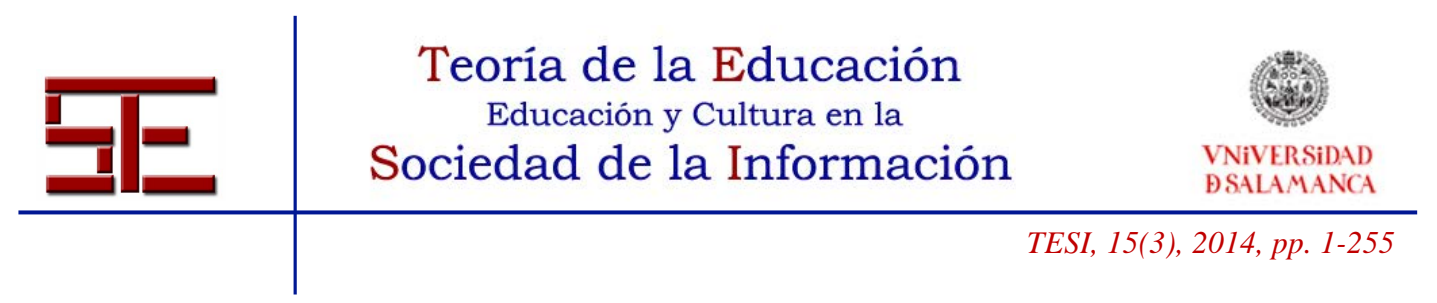

- Existe un rechazo social generalizado hacia el uso de videojuegos en el colegio motivado por su adicción y posible presencia de contenidos violentos.

- No se valora suficientemente la funcionalidad educativa del juego y, en consecuencia, de los videojuegos.

- Los maestros y educadores no disponen de suficiente experiencia o formación para utilizar e integrar los videojuegos en sus didácticas.

- Faltan instrumentos y métodos para evaluar y cuantificar los resultados y aprendizajes de los alumnos con el uso de videojuegos.

- Temor del profesorado a que los padres piensen que, si sus hijos también juegan en clase, están perdiendo el tiempo, lo que genera inseguridad.

Para que el proyecto fuese ágil, se dividió en tres etapas a lo largo del curso y se clasificaron las diversas tareas entre las mencionadas etapas. Los alumnos trabajaron por parejas, excepto dos equipos que estuvieron constituidos por tres componentes.

En la etapa inicial, correspondiente al primer trimestre del curso 2012-2013, se les propuso que escogieran un minijuego de Física y otro de Química de la lista propuesta, así como que buscaran otro minijuego adicional. Para evitar desviaciones se les indicó que descartaran minijuegos de contenidos violento, sexista, discriminatorio, que incitasen al juego de azar o apuestas, que contuviesen lenguaje soez y que estimulasen el miedo o el consumo de drogas.

Los tres minijuegos seleccionados fueron sometidos al examen de cada equipo según un modelo que se les suministró. En esta fase analizaron las consideraciones técnicas (en la que se analizaba la adecuación del formato, la rapidez a la hora de cargarse el minijuego, la calidad de la imagen, del sonido, la personalización, la intuición de la interfaz o la superación del desafío planteado), contextuales (donde se evaluaba la adecuación del minijuego a su edad, el nivel del lenguaje utilizado, el desarrollo de otro idioma o la adaptación para alumnos con discapacidad) y clasificaron los minijuegos (tipo de minijuego seleccionado según la clasificación propuesta). Las dos primeras consideraciones utilizaron para su análisis una escala de 1 (baja) a 5 (excelente).

Además, debieron elaborar una pequeña guía en español sobre cómo se juega y algunos "trucos" para avanzar más en cada minijuego. Todo ello lo presentaron utilizando el formato de una revista digital.

En la etapa intermedia, correspondiente al segundo trimestre del curso 2012-2013, continuaron con el análisis emprendido en la fase anterior, completándolo con las consideraciones pedagógicas (en la que se analizaba la curva de aprendizaje del minijuego, la relación con el contenido de Física y Química o la potenciación de la creatividad de los jugadores), la evaluación del minijuego (que abarcaba dos subepígrafes, la comprensión general del minijuego y la comprensión de los problemas

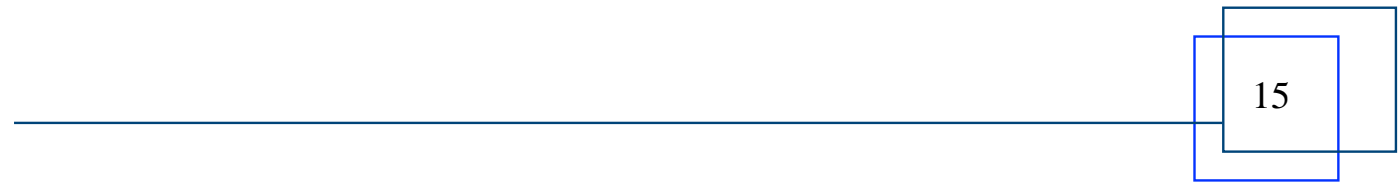




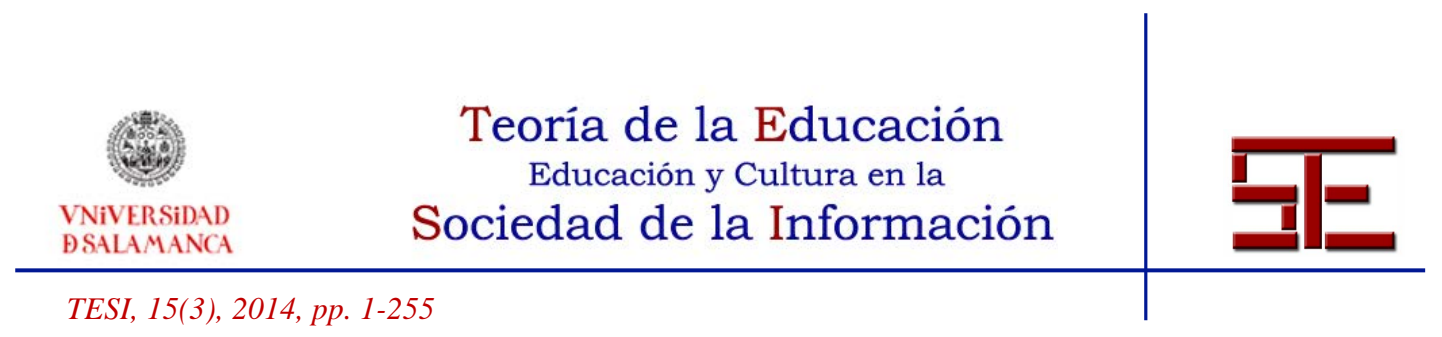

planteados por el minijuego) y la recomendación final otorgada al minijuego. Tanto las consideraciones pedagógicas como la recomendación final sobre el minijuego emplearon para su análisis una escala de 1 (baja) a 5 (excelente). La evaluación del minijuego se efectuó mediante respuestas a preguntas cortas del tipo ¿cuál es el objetivo del minijuego?, ¿cuáles son los principales retos a los que te enfrentas?, ¿cuáles son los principales problemas a los que te enfrentas en el minijuego?, ¿cuál es tema principal de este?, ¿crees que se puede aplicar la temática del minijuego a la realidad? o ¿qué has aprendido con este minijuego? Además, representaron uno de los minijuegos seleccionados mediante una fotografía interactiva.

En la etapa final, correspondiente al tercer trimestre del curso 2012-2013, realizaron un test multimedia, de opción múltiple, autocorregible, basado en uno de los minijuegos seleccionados y que tuviera relación con contenidos de Física y Química, sirviendo de repaso para dichos contenidos; un cartel de presentación del trabajo realizado a lo largo del curso y el cuestionario de autoevaluación.

\subsection{Recursos empleados}

Se ha procurado utilizar tecnologías y materiales de libre acceso para la realización de las diferentes actividades. Así, la selección de minijuegos se realizó en función de los que estaban disponibles gratuitamente en Internet. El profesor suministró una batería de minijuegos a los estudiantes a modo de ejemplo para orientar la búsqueda.

Los documentos de los análisis de minijuegos realizados por los estudiantes, en su totalidad, emplearon la suite de Office (Word) y para transformar los documentos generados a formato pdf, conversores libres.

El software Issuu fue el seleccionado para la elaboración de la revista digital. Es una aplicación fácil, sencilla de utilizar y gratuita.

Para la elaboración de una imagen representativa del minijuego seleccionado por cada equipo y que contuviese, al menos, cuatro interactividades, se utilizó Thinglink. Es una herramienta Web 2.0, gratuita y que permite crear representaciones fotográficas interactivas, enriquecidas con vídeos, música, sonido, texto, etc. El resultado generado se comparte por Facebook, Twitter y por mail, siendo este último el medio utilizado en la experiencia.

El test interactivo se generó utilizando la aplicación MyStudiyo. Es una herramienta Web 2.0, gratuita en parte. Permite crear test interactivos, enriquecidos con vídeos, música, imagen, etc. Además, se puede añadir feedback a cada respuesta, sea acertada o no, y se puede hacer que las preguntas aparezcan en un orden fijo o aleatorio. El resultado se comparte por Facebook y por mail, siendo este último el medio usado en el proyecto.

16 


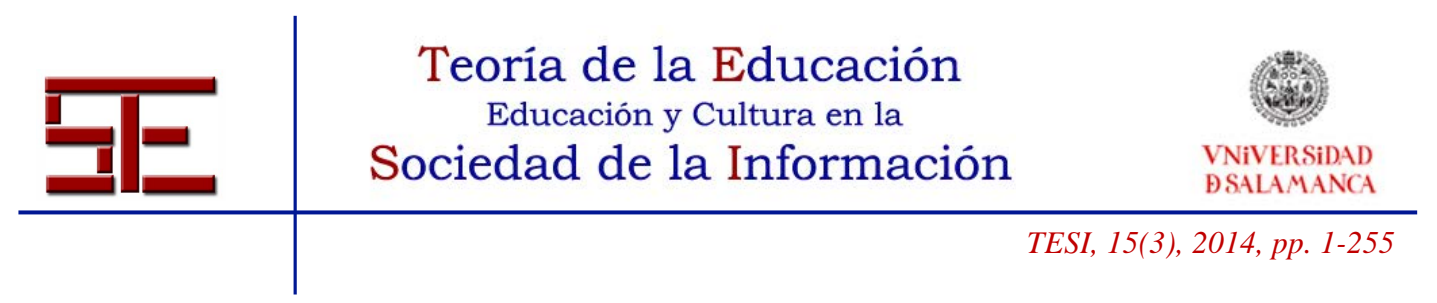

El cartel de presentación del trabajo elaborado se realizó con la herramienta piZap. Es otra herramienta Web 2.0, gratuita y que no necesita registro. Se trata de un editor de fotos, que permite añadir efectos, realizar collages, personalizar textos, etc. Una vez editada la imagen, permite la descarga de esta, en formato jpg, al ordenador.

El cuestionario de autoevaluación se suministró en Word y los estudiantes lo rellenaron y convirtieron en un documento pdf.

Los canales de comunicación propuestos para ser utilizados por los alumnos y el profesor fueron dos: la wiki de la asignatura, a la cual se subía la información general del proyecto y la red social Edmodo.

Edmodo es una red social de microblogging, basada en el uso de mensajes de texto cortos; por ejemplo, la más conocida es Twitter. Según (Quintanal, 2012) estas redes:

\begin{abstract}
"Presentan la gran limitación de la escasez de elementos de interacción social, así como de mecanismos que permitan dotar de una identidad específica y particular a la propia red. Este hecho es importante cuando se trabaja con niños y adolescentes, pues les gusta compartir fotos, vídeos, actividades o eventos en los que participan, así como poder personalizar su perfil.

De entre las redes educativas de microblogging destaca Edmodo. Presenta, al igual que otras redes, la ventaja de la privacidad de los estudiantes y de su gratuidad. Además, para acceder a la red creada con este servicio sólo se necesita un código que proporciona el profesor y no son necesarios para el registro ni la dirección del correo electrónico ni datos personales relevantes.

Dispone de una serie de herramientas diseñadas para la educación. Destacan las asignaciones de tareas, las entregas de éstas, el calendario de entrega de tareas, la calificación de éstas, posibilidad de hacer públicas las páginas o comentarios que estime el profesor, la biblioteca y la gestión de grupos de la red. Además, dispone de servicios de alerta vía móvil o Twitter. Una ventaja adicional es la posibilidad, si se desea, de permitir el acceso de las familias de los estudiantes a la red mediante un código diferente al de los alumnos". (Quintanal, 2012, 217).
\end{abstract}

\title{
7. LOGROS DEL PROYECTO
}

Se presentará en este epígrafe los resultados, el impacto y su evaluación después de la realización de esta experiencia.

\subsection{Los resultados}

Se inician con la producción generada por los estudiantes. Se constituyeron 20 equipos de trabajo, de los cuales 18 eran parejas y los dos restantes estaban conformados por tres integrantes. Cada equipo seleccionó y analizó tres minijuegos educativos, relacionados con la Física y/o la Química, lo que supuso un total de 51 minijuegos analizados; elaboró una revista digital; una imagen representativa de uno de los minijuegos que contuviese, al menos, cuatro interactividades; un test multimedia con un límite de ocho cuestiones de opción múltiple y basado en alguno de los minijuegos 


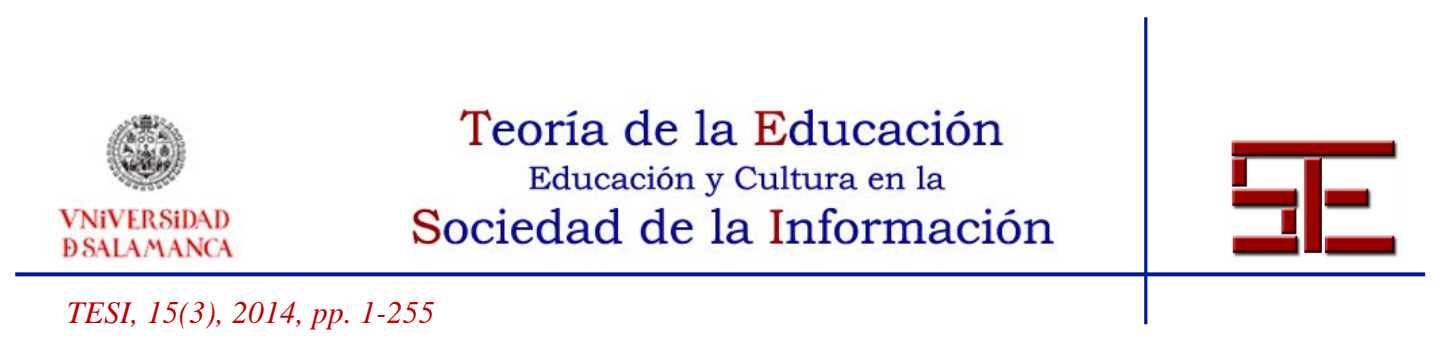

analizados; un cartel de presentación del trabajo realizado y los cuestionarios de autoevaluación rellenos individualmente por cada integrante del equipo de trabajo.

Así, la relación de minijuegos seleccionados para Química fue la siguiente: Chemical attack, Infect evolve repeat, Doodle God, Doodle God 2, Atomix, Atomic puzzle, Magnesium gardens, Elements, Pasapalabras-Física y Química 1, Ahorcado, Juego de Iron Man 2, Chaos reactor, Target practice quiz Chemistry y More zombies.

La selección de minijuegos de Física estuvo constituida por: Mario basketball, FMX Team, Epic coaster, Sumo ball, Truck loader 3, Desafio snowboard, Downhill Stunts, Stan James, Icycle, What a shot, Fuerza oscura, Bubble, Green physics 3, Robin Hood al rescate, Tarzán y Jane, Tiro olímpico, Cut and kill Halloween, Medieval golf, Go kart go! Nitro!, Stitch tiki bowl, Prison break, Physics cup 2, Physics cup 3, Alunizaje de precisión, Micro racers, Connect it, N3wton, Blast off, Air transporter, Wake up the box, Rescate lunar, Fanged fun: Level pack, Balloon pets, Alunizaje, Portal, Perfect balance 2 y Fun da Vinci.

La Figura 3 muestra un ejemplo de cartel de presentación efectuado por los alumnos.

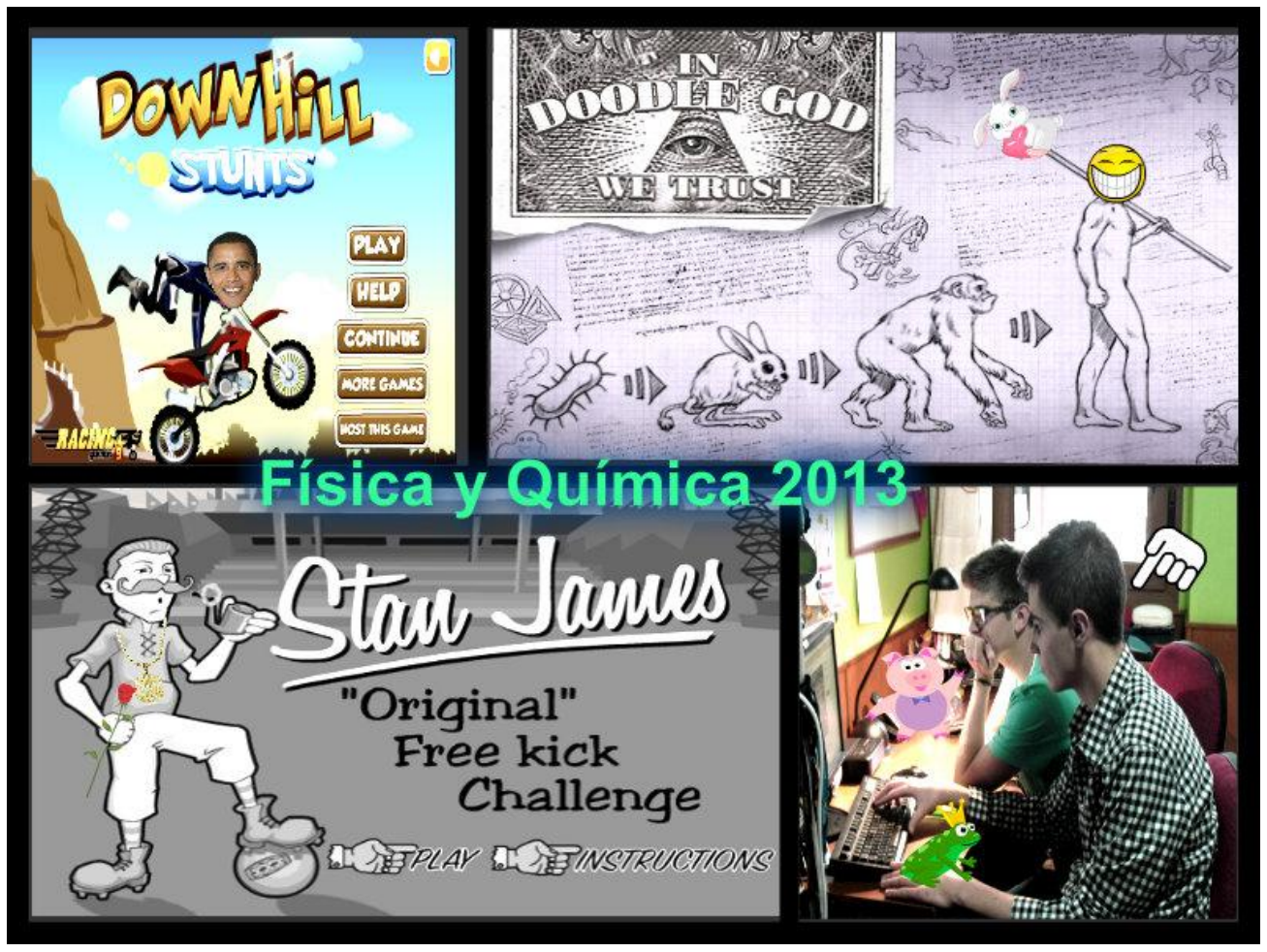

Figura 3. Cartel de presentación de un trabajo efectuado sobre minijuegos educativos (Fuente propia, 2013).

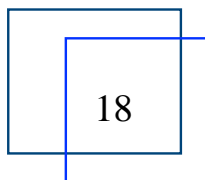




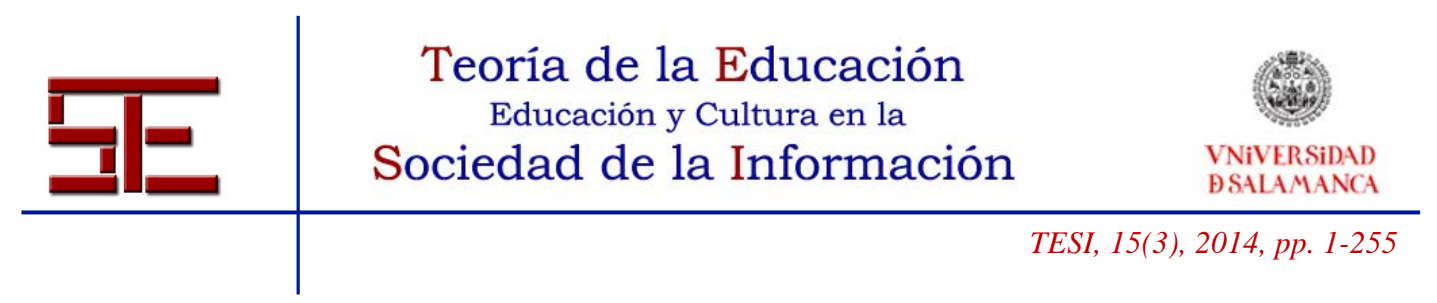

\subsection{Impacto generado y su evaluación}

El impacto del proyecto realizado se caracterizó y evaluó mediante un cuestionario de autoevaluación que rellenaron y entregaron los estudiantes. Este cuestionario constaba de 14 ítems, donde 13 de ellos eran calificables de 1 a 5 (1-valoración mala, 2valoración regular, 3-valoración buena, 4-valoración muy buena y 5-valoración excelente) y uno de los ítems era opcional y de redacción libre.

De los 13 ítems, 6 eran concernientes a las tareas efectuadas, 5 a las herramientas tecnológicas utilizadas, 1 a la temática trabajada y otro sobre la satisfacción personal de las actividades desarrolladas.

La Figura 4 muestra las medias obtenidas sobre la apreciación aportada por los estudiantes para las tareas efectuadas.

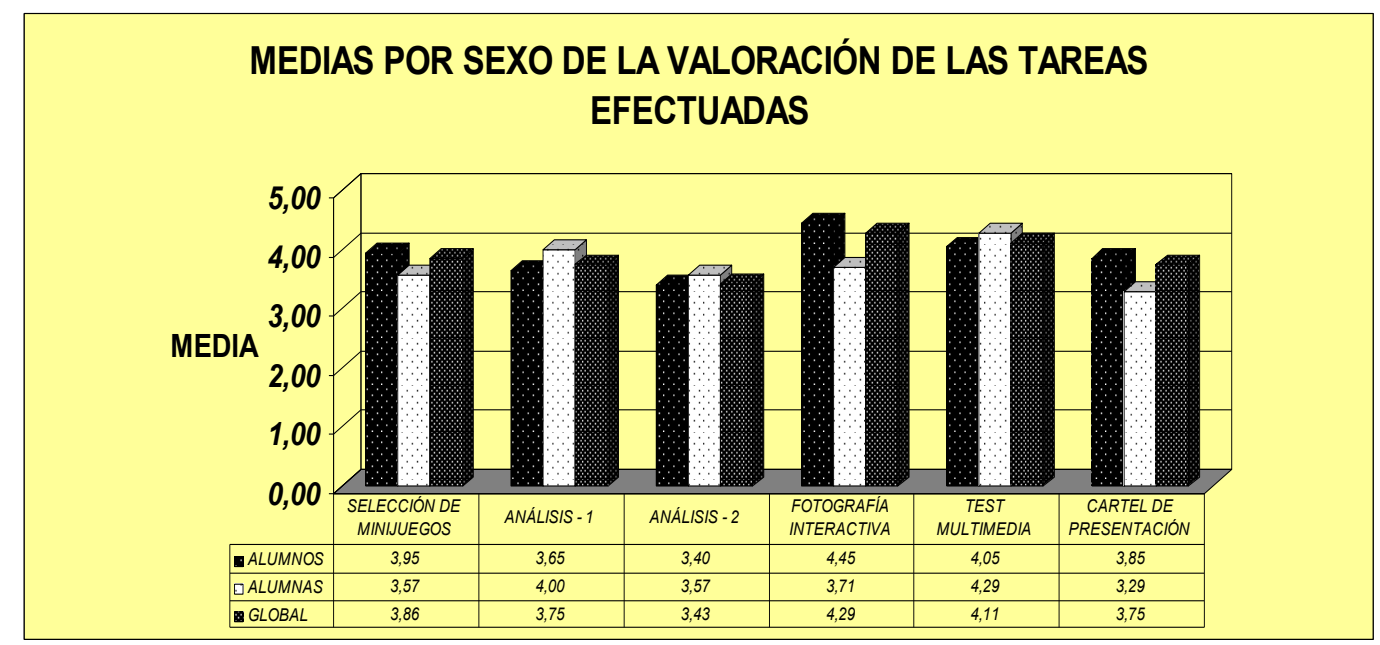

Figura 4. Relación de medias, por sexo y global, sobre la valoración de las tareas realizadas (Fuente propia, 2013).

Se comprueba que, de las respuestas extraídas de los cuestionarios de autoevaluación, las tareas se califican con etiquetas buena o muy buena. Las más apreciadas son la realización de la fotografía interactiva (media global de 4,29) y del test multimedia (media global de 4,11). La que menos, el análisis de los minijuegos en sus consideraciones pedagógicas y de evaluación (media global de 3,43). Por sexo, las alumnas difieren de la tendencia general al valorar más el test multimedia (media de

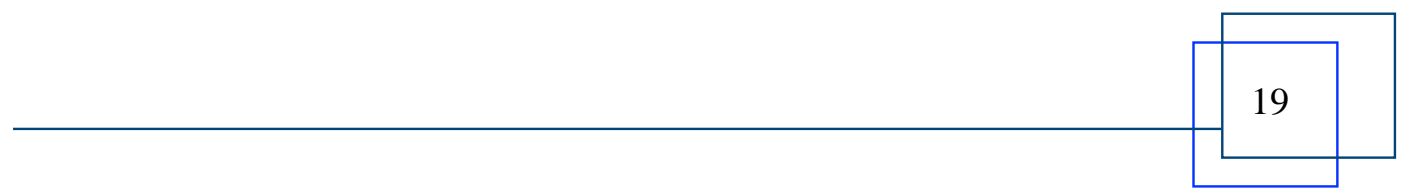




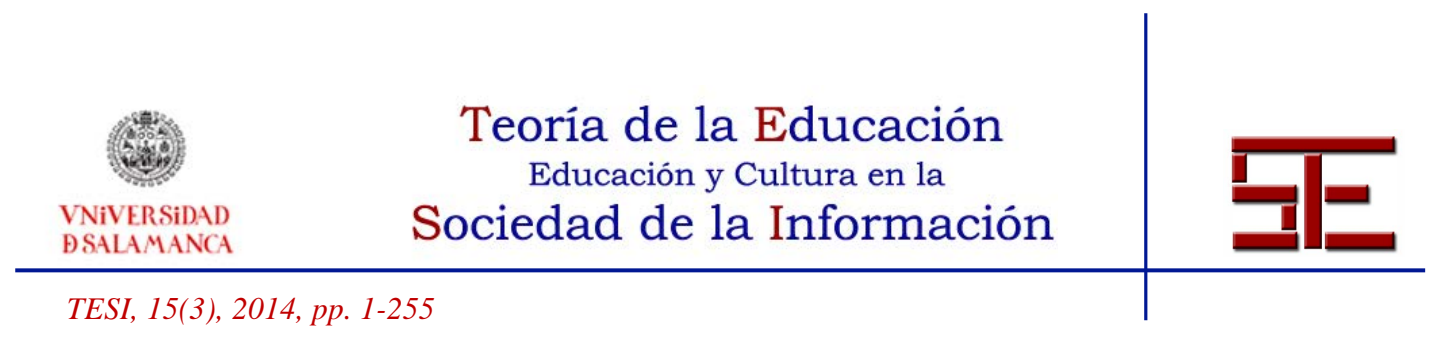

4,29) y la realización del análisis en sus consideraciones técnicas, contextuales y clasificatorias (media de 4,00), siendo la tarea menos apreciada la realización del cartel de presentación (media de 3,29).

La Figura 5 manifiesta las medias obtenidas sobre la apreciación aportada por los estudiantes para las herramientas empleadas.

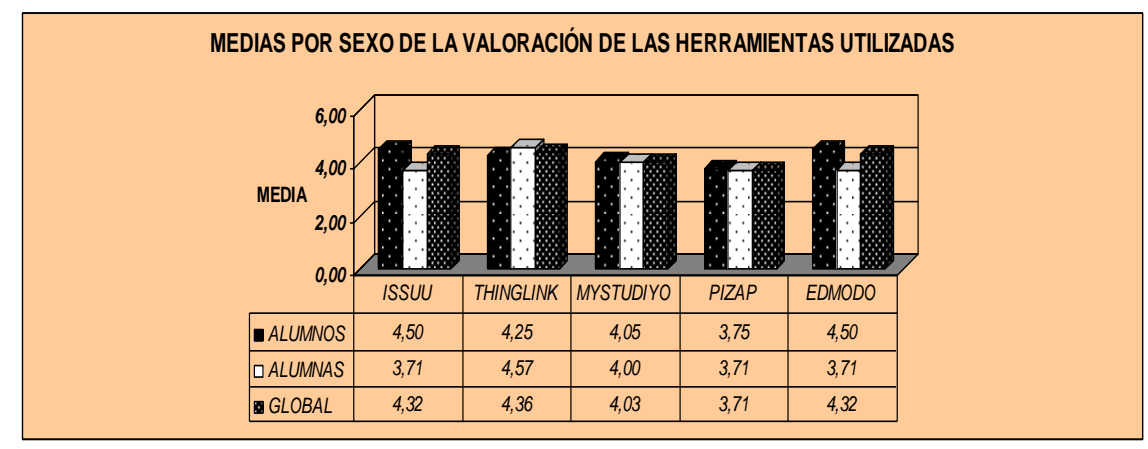

Figura 5. Relación de medias, por sexo y global, sobre la valoración de las herramientas aplicadas (Fuente propia, 2013).

Se deduce que las herramientas se califican con etiquetas buena, muy buena y casi excelente. Las más ponderadas son Thinglink (media global de 4,29), software para realizar fotografías interactivas; Edmodo (media global de 4,32), como canal de comunicación y de almacén de tareas e Issuu (media global de 4,32), para la realización de la revista digital. La menos valorada ha sido piZap (media global de 3,71), herramienta para tratar imágenes. Por sexo, las alumnas nuevamente divergen de sus homólogos masculinos al valorar Thinglink (media de 4,57) en mayor cuantía que los alumnos (media de 4,25), coincidiendo aproximadamente en su apreciación por MyStudiyo y piZap, aunque su valoración es inferior (media de 3,71) a la de los estudiantes masculinos (media de 4,50) para Edmodo e Issuu. A diferencia de los alumnos, no aparece claramente una herramienta que sea menos apreciada.

Con respecto a la valoración de la temática escogida, los minijuegos educativos, la media obtenida fue de 3,93; siendo más alta para los alumnos, 4,00 que para las alumnas, 3,57.

La satisfacción personal de los estudiantes por los trabajos realizados fue muy alta. Así, la media general obtenida fue de 4,32. Por sexo, los alumnos consiguieron una media de 4,40 y las alumnas de 4,00 .

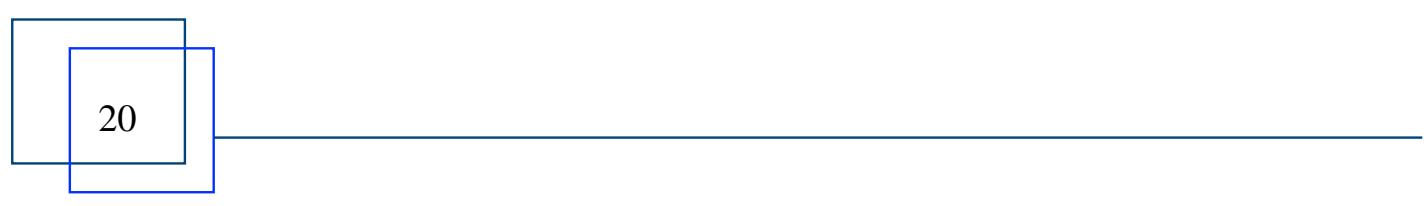




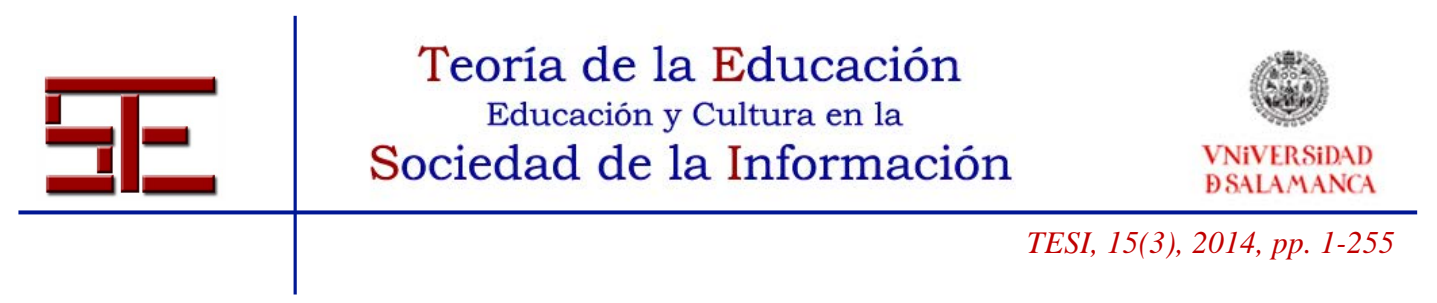

El profesor que realizó esta investigación destacó como impactos importantes el incremento de la motivación del alumnado, traslucido en la mejora del rendimiento académico (se apreció un incremento medio generalizado y sostenido en las calificaciones de la materia durante las tres evaluaciones del curso) y en una mejora de la autoconfianza de los estudiantes, y la mejora de distintas competencias como las sociales, intelectuales, espacio-temporales y la concentración, así como la competencia digital.

\section{CONCLUSIONES}

El uso de minijuegos ha permitido aumentar la motivación de los estudiantes, así como afianzar su autonomía, autoconfianza y autoestima; por ello, ha contribuido a cumplir con los objetivos educativos en términos de contenidos, competencias (sobre todo, sociales) y valores.

El proyecto ha favorecido el respeto de los ritmos de aprendizaje, el trabajo en equipo y el desarrollo de las competencias intelectuales, pudiéndose utilizar en coordinación con materiales educativos más tradicionales, lo que ha supuesto una forma de recompensa del aprendizaje.

Se han potenciado y desarrollado las destrezas TIC del alumnado, así como la visión de que los estudiantes generan contenido científico que pueden compartir con sus compañeros; de ahí que el trabajo realizado hay reducido costes y esfuerzo, manteniendo resultados y calidad.

El proyecto es transferible a otros niveles y áreas. Así, si se emplean minijuegos, se puede hacer en $3^{\circ}$ y $4^{\circ}$ de ESO, Educación Primaria e Infantil. Las áreas implicadas en Educación Primaria y Secundaria pueden ser Lengua (materna y foráneas), Historia, Geografía, Matemáticas y Biología.

Si los minijuegos no son aplicables, se pueden usar videojuegos comerciales. En el caso de emplear videojuegos comerciales se recomienda tener en cuenta el contexto en el que se usarían; es decir, la dificultad de compaginar el juego con la programación, la falta de ordenadores disponibles, la organización de las sesiones lectivas, la actitud del centro y de las familias hacia los videojuegos, el coste de estos y de sus licencias. Se debe añadir al razonamiento expuesto, la cuidadosa selección de los videojuegos basándose en sus cualidades pedagógicas. Aunando todo ello, implica un coste de tiempo elevado.

El uso de los videojuegos comerciales tiene como premisas aprender, memorizar, colaborar, explorar, etc., constituyendo aspectos relevantes para el análisis crítico de otros contenidos curriculares, por lo que los videojuegos se podrían incorporar sin problemas en el diseño didáctico de estos contenidos curriculares.

Por último, indicar que tanto el profesor como los alumnos consideran globalmente que

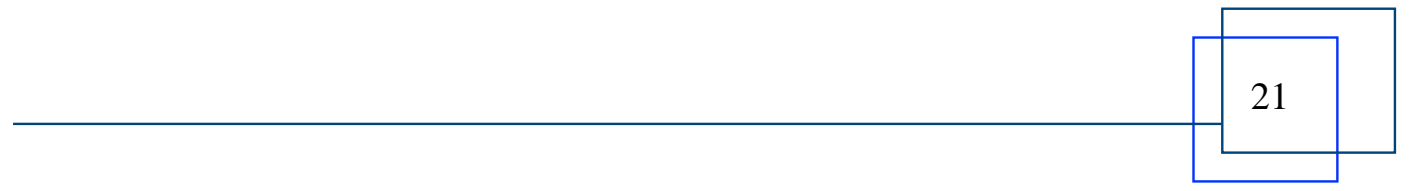




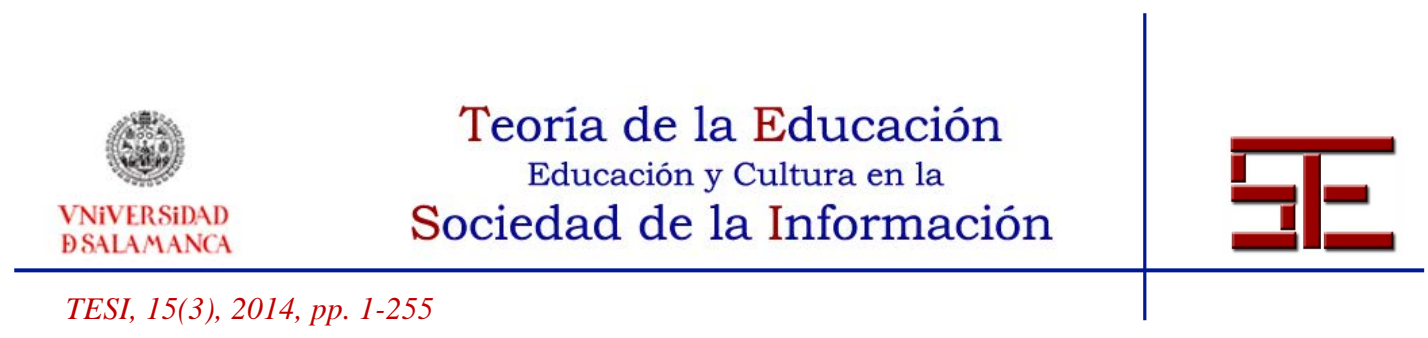

el proyecto realizado ha sido muy satisfactorio.

\section{REFERENCIAS}

Del Castillo, H., Herrero, D., García, A. B., Checa, M., Monjelat, N. (2012). Desarrollo de competencias a través de los videojuegos deportivos: alfabetización digital e identidad. RED. Revista de Educación a Distancia, 33. Número monográfico dedicado a videojuego $y$ aprendizaje. Extraído el 18 enero, 2014 de <http://www.um.es/ead/red/33/>.

Felicia, P. (2009). Digital games in schools: A handbook for teachers complements the study. How are digital games used in schools? (Project European School net's Games in Schools). Bruselas: EUN Partnership AISBL. Extraído el 18 enero, 2014 de <games.eun.org/upload/gis_handbook_en.pdf>.

Gee, J. P. (2003). What video games have to teach us about learning and literacy? New York: Palgrave Macmillan.

Gee, J. P. \& Hayes, E. R. (2010). Games and women: The Sims and $21^{\text {st }}$ century learning. New York: Palgrave Macmillan.

Gómez del Castillo, M. T. (2007). Videojuegos y transmisión de valores. Revista Iberoamericana de Educación, 43 (6), 1-10.

Gros, B. (2012, febrero). Estrategias de aprendizaje basado en videojuegos en la formación del profesorado. Actas del I Congreso Internacional Videojuegos y Educación (CIVE 2012), 5-15, L'Alfàs del Pi, Alicante. Extraído el 18 enero, 2014 de <http://www.uv.es/ordvided/ACTAS/ACTAS\%20CIVE\%202012.pdf〉.

Jenkins, H. (2006a). Converge culture: where old and new media collide. New York: New York University.

Jenkins, H., Purushotma, R., Clinton, K., Weigel, M., Robison, A. (2006b). Confronting the Challenges of Participatory Culture: Media Education for the 21st Century. Chicago, IL: The MacArthur Foundation.

Livingstone, S. (2002). Young people and new media: childhood and the changing media environment. Thousand Oaks, CA: Sage.

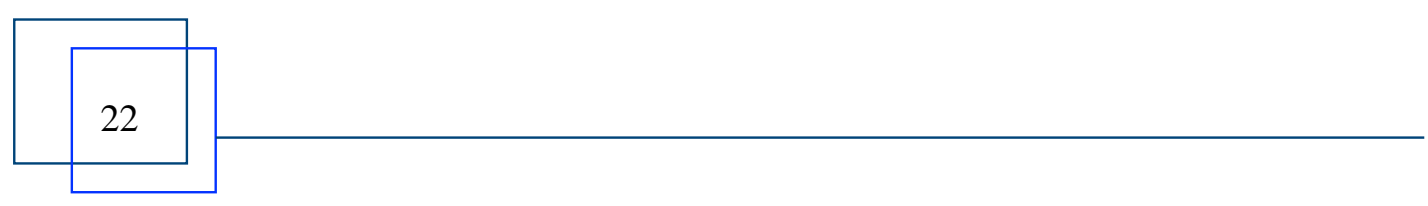




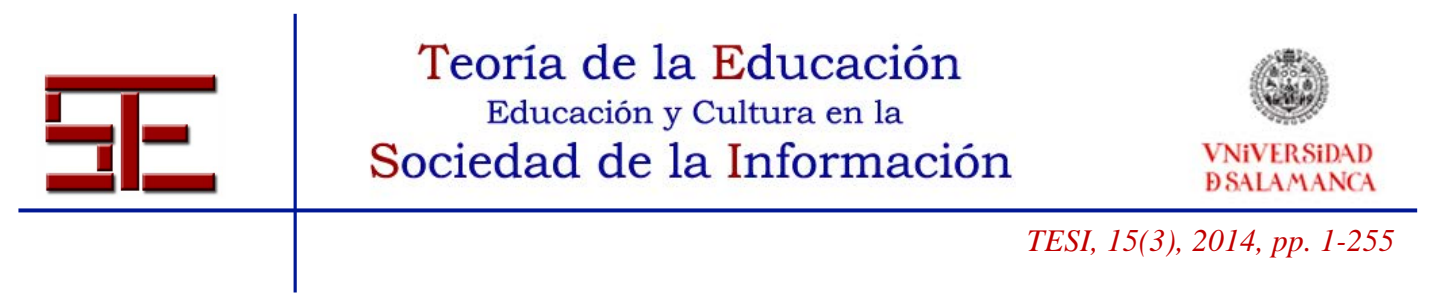

Quintanal, F. (2012). Edmodo en Física y Química de Bachillerato. En R. Peña (Ed.) y colaboradores, Cómo enseñar utilizando las redes sociales (pp. 214-234). Tarragona: Editorial Altaria.

Revuelta, F. I. \& Guerra J. (2012). ¿Qué aprendo con videojuegos? Una perspectiva de meta-aprendizaje del videojugador. RED. Revista de Educación a Distancia, 33. Número monográfico dedicado a videojuego y aprendizaje. Extraído el 18 enero, 2014 de $<$ http://www.um.es/ead/red/33/>.

Vida, T. \& Hernández, T. (2005). Los videojuegos [Versión electrónica]. Aula de Innovación Educativa, 147, 35-40. 